\begin{tabular}{|c|c|}
\hline Title & $\begin{array}{l}\text { Effect of two-stage injection on unburned hydrocarbon and carbon monoxide emissions in smokeless low-temperature } \\
\text { diesel combustion with ultra high exhaust gas recirculation }\end{array}$ \\
\hline Author(s) & Li, Tie; Suzuki, Masaru; Ogawa, Hideyuki \\
\hline Citation & $\begin{array}{l}\text { International Journal of Engine Research, 11(5), 345-354 } \\
\text { https://doi.org/10.1243/14680874JER585 }\end{array}$ \\
\hline Issue Date & 2010-10-01 \\
\hline Doc URL & http:/hdl. handle.net/2115/47389 \\
\hline Rights & $\begin{array}{l}\text { The final, definitive version of this paper has been published in International Journal of Engine Research, 11(5), Oct. } \\
2010 \text { by SA GE Publications Ltd, All rights reserved. @ Institution of Mechanical Engineers }\end{array}$ \\
\hline Type & article (author version) \\
\hline File Information & IJER11-5_345-354.pdf \\
\hline
\end{tabular}

Instructions for use 
Cover page

Title:

The Effect of Two-Stage Injection on Unburned Hydrocarbon and Carbon Monoxide Emissions in Smokeless Low Temperature Diesel Combustion with Ultra-High Exhaust Gas Recirculation

Authors and affiliations:

Tie Li ${ }^{1}$, Masaru Suzuki ${ }^{2}$, and Hideyuki Ogawa ${ }^{1}$

${ }^{1}$ Division of Energy and Environmental Systems, Graduate School of Engineering, Hokkaido University

${ }^{2}$ Toyota Motor Corporation

Corresponding address:

Dr. Tie Li

Division of Energy and Environmental Systems,

Graduate School of Engineering, Hokkaido University

N13 W8, Kita-ku, Sapporo 060-8628, Japan

Tel: +80-11-706-6384, Fax: +81-11-706-6384

Email: litie@eng.hokudai.ac.jp 


\title{
The Effect of Two-Stage Injection on Unburned Hydrocarbon and Carbon Monoxide Emissions in Smokeless Low Temperature Diesel Combustion with Ultra-High Exhaust Gas Recirculation
}

Tie $\mathrm{Li}^{1}$, Masaru Suzuki ${ }^{2}$, and Hideyuki Ogawa ${ }^{1}$

${ }^{1}$ Division of Energy and Environmental Systems, Graduate School of Engineering, Hokkaido University ${ }^{2}$ Toyota Motor Corporation

\begin{abstract}
:
The unburned hydrocarbon (UHC) and carbon monoxide (CO) emissions from smokeless low temperature diesel combustion (LTC) with ultra-high exhaust gas recirculation (EGR) can be attributed to lowered combustion temperatures as well as to under-mixing of fuel-rich mixture along the combustion chamber walls, overly-mixed fuel-lean mixture at the spray tails, and fuel missing the piston bowl and entering the squish zones. Two-stage injection has the potential to reduce UHC and CO emissions through decreasing the ratios of these mixtures. This study investigates the effects of two-stage fuel injection by varying the dwell between the two injections as well as the fuel quantity in each injection on the UHC and CO emissions, experimentally with a single cylinder diesel engine. With the optimized dwell and injection ratio, two-stage injection can reduce the UHC and CO emissions, but these emissions are still at high levels in the ultra-high EGR smokeless LTC regime. Computational fluid dynamics simulations of the in-cylinder spray and mixture formation processes showed that with the two-stage injection, over-rich mixture in the squish zones can be significantly avoided but the over-lean mixtures at center of the combustion chamber are little reduced, and these would likely be a significant source of UHC and CO emissions.
\end{abstract}

Keywords: Diesel Engine, Low Temperature Combustion (LTC), Exhaust Gas Recirculation (EGR), Two-Stage Injection, Unburned Hydrocarbon, Carbon Monoxide 


\section{INTRODUCTION}

Diesel engines have the highest thermal efficiency among internal combustion engines, and a promotion of diesel utilization could be advantageous to reduce carbon dioxide emissions. However, owing to the trade-off between nitrogen oxides (NOx) and soot emissions from the jet-mixing-controlled diesel combustion [1], it appears unlikely that conventional diesel engines can meet the increasingly stringent emission regulations coming into force in many industrialized countries, without expensive after-treatment systems [2-3], despite the significant reductions of engine-out emissions with advanced technologies including elevated injection pressure, cooled exhaust gas recirculation (EGR), and variable-geometry turbochargers. Nevertheless, to maintain the functioning of exhaust aftertreatment devices and fuel economy in relation to vehicle running costs, further reductions in engine-out emissions through improved combustion technologies are urgently required.

Premixed compression-ignition low-temperature combustion (LTC) engines can deliver both high efficiencies and ultra-low NOx and soot emissions [3-4]. Due to the low volatility of diesel fuels, most research into diesel LTC is focused on direct injection strategies with either very-early injections for lean mixtures [5-7] or moderately-advanced (or retarded) injections with large quantities of cooled EGR [8-19]. In the very-early injection strategies, specially designed injector or injection strategies are necessary to avoid oil dilution by liquid spray impinging upon the cylinder walls. In addition to increased engine costs, however, engine performance would suffer with the specially designed systems when switched from LTC to conventional combustion at higher loads, since these strategies are limited to partial load operations.

Fuel injection systems for conventional diesel combustion can be readily utilized for moderately-advanced injections without concerns about cylinder wall wetting by the spray, but large quantities of cooled EGR are generally necessary to achieve smokeless LTC. Although EGR is very effective to reduce NOx emissions in diesel engines, because of the trade-off between NOx and soot emissions, EGR is conventionally limited to relatively low rates in spite of the potential for further reductions in NOx emissions. Recent research has demonstrated that ultra-high rates (>50\%) of EGR can help to extend ignition delays as well as reduce combustion temperatures, and as a consequence smokeless and ul- 
tra-low NOx combustion can be accomplished with ultra-high EGR [9-19].

However, there are dramatic increases in unburned hydrocarbon (UHC) and carbon monoxide (CO) emissions as well as unacceptable deteriorations in combustion efficiency with ultra-high EGR LTC [13-19]. Besides the common sources of UHC and CO emissions such as injector dribbling at the needle opening and closing events, and over-mixing of fuel during the ignition delay period in conventional diesel combustion [20-21], there are further causes contributing to the increases of UHC and CO emissions in ultra-high EGR LTC. Firstly, bulk quenching of mixture during the gas expansion owing to lowered peak combustion temperatures with ultra-high EGR can be a significant source of UHC and CO emissions. Next, fuel-air over-mixing at the spray tails after the end of injection has been observed in experiments with both constant-volume vessels [22] and optical engines [23-24] under conditions simulating diesel LTC, and the mixtures here are too lean to support complete combustion, becoming a source of UHC and CO emissions. Moreover, owing to the increases in ignition delays with ultra-high EGR, advanced fuel injection is commonly necessary to avoid deterioration in the torque output [16]; as a result, fuel missing the piston bowls and entering the squish zones can be considered as a further source of UHC and CO emissions [14, 18-19, 23-24].

Split injections are effective to reduce smoke emissions in diesel engines [26-27], with the reduction largely attributed to improved fuel-air mixing processes [28-29]. Here two-stage injection can also be expected to reduce UHC and CO emissions by reducing over-lean mixture at the spray tails as well as by avoiding fuel-rich mixture entering the squish zone. The effects of two-stage injection on the exhaust gas emissions from diesel LTC with ultra-high EGR have been investigated [30-31]. In these studies, however, there were non-negligible increases in smoke emissions in the ultra-high EGR LTC regime, which can be attributed to the fact that ignition occurred in the mixture resulting from the first injection and fuel from the second injection was burned with insufficient mixing and at high temperature.

The objective of this study is to investigate the effect of two-stage injection on the UHC and CO emissions from smokeless and ultra-low NOx diesel combustion with large quantities of cooled EGR. Ignition of the first injected fuel was circumvented by using a low cetane number fuel. Engine bench experiments were conducted to examine the characteristics of the combustion and exhaust gas emissions 
with the two-stage injection, and three dimensional computational fluid dynamics (3-D CFD) simulations were carried out to evaluate the effect of the two-stage injection on the spray and mixture formation processes in a low oxygen environment simulating engine operation with 60\% EGR.

\section{EXPERIMENTAL SETUP}

\subsection{Test engine and operation conditions}

Table 1 shows the specifications of the engine and Table 2 shows the experimental conditions. Experiments were conducted on a single cylinder, two valves, naturally aspirated, four-stroke, one liter direct injection (DI) diesel engine with a common rail fuel injection system; a compression ratio of 16.0 was used. The injection pressure was set at $120 \mathrm{MPa}$, and the fuel injection quantity at $32 \mathrm{~mm}^{3} /$ stroke, corresponding to a 50\% load (indicated mean effective pressure (IMEP): $0.5 \mathrm{MPa}$ ) under the condition without EGR. The injection timing ( $\left.\mathrm{t}_{\mathrm{SOI}}\right)$ was dynamically controlled, as will be detailed in the Results and Discussion section. The engine speed and coolant temperature were fixed at $1320 \mathrm{rpm}$ and $80{ }^{\circ} \mathrm{C}$, respectively. The EGR was realized by diverting part of the cooled exhaust gas into the intake port with gate valves. The EGR rate was defined by the volume fraction of EGR gas in the total intake charge under standard conditions. The temperature of the intake mixture of fresh air and EGR gas was $30 \pm 3{ }^{\circ} \mathrm{C}$ under all operating conditions.

\subsection{Test fuels}

Table 3 shows the properties of the test fuels. The n-paraffins (NP) and iso-paraffins (IP) used as the baseline fuels have similar physical properties, for the density, kinematic viscosity, and distillation temperatures affecting the spray and mixture formation processes. Reference fuels (RF) were obtained by blending NP and IP in various volume fractions as shown by the number following RF. The cetane number of the reference fuel was calculated based on the volumetric fraction. To avoid ignition by the first injection, RF3-7 (cetane number 42) was used in the experiments with two-stage injection, and the other fuels were used to provide basic data for comparison between the characteristics of ultra-high EGR LTC with single and two-stage injection. 


\subsection{Analysis of indicator diagrams and exhaust gas emissions}

The in-cylinder pressure was measured by a water-cooled piezoelectric pressure transducer (6061B: KISTLER), and data for 90 cycles were averaged for the indicator analysis. The rate of heat release (ROHR) was calculated from the pressure data following a procedure similar to that in [32]. The ROHR was integrated from $-30{ }^{\circ} \mathrm{CA}$ ATDC (degree crank angle after top dead center) to just prior to the exhaust valve opening to obtain the cumulative apparent heat release, which was normalized by the maximum value. The ignition timing is defined as the crank angle of $5 \%$ of the normalized cumulative heat release.

Exhaust gas was sampled about $1500 \mathrm{~mm}$ downstream from the engine exhaust valve, and was analyzed with an automotive exhaust gas analyzer (MEXA-9100DEGR: HORIBA) including a non-dispersive infrared absorption method for $\mathrm{CO}$, a chemical luminescence detector for NOx, and a heated flame ionization detector for UHC. The smoke concentration, which is a good estimate of the soot or insoluble fractions in diesel particulate emissions, was measured with a Bosch-type smoke meter (DSM-20AN: ZEXEL) using the light reflected by the filter paper where smoke was sampled. The basic value is $-3.5 \%$, and a negative value is obtained when there is no smoke or the smoke concentration is very low. The intake oxygen concentration $\left(\mathrm{O}_{2 \text { in }}\right)$ was measured with a paramagnetic-type oxygen tester (POT-101: SHIMADZU).

\section{NUMERICAL SIMULATION METHOD}

To investigate the distributions of the in-cylinder fuel-air mixture concentrations in the low oxygen environments, numerical simulations were conducted using the 3-D CFD code AVL FIRE 8.2. Table 4 shows the sub-models for spray and mixture formation and the initial conditions. The mesh of about 30000 cells used in the CFD simulation is shown in Fig. 1. The engine specifications and operating conditions in the simulations were identical with those in the experiments, and the boundary conditions were set so that the temperature and pressure traces during the compression stroke for the simulation and measurements matched. The "diesel fuel” parameter setting in the FIRE package, which has physi- 
cal properties similar to the test fuels in the experiments, was used. The calculations were executed from the engine intake valve closing to $10^{\circ} \mathrm{CA}$ ATDC.

\section{RESULTS AND DISCUSSION}

\subsection{Effects of two-stage injection on UHC and CO emissions}

Figure 2 shows the effects of cetane number and injection timing $t_{i n j}$ on the ignition delay and premixing time $\theta_{\text {pre }}$ for two intake oxygen concentrations, $12 \%$ and $9 \%$ (50\% and $60 \%$ EGR). Here the $12 \% \mathrm{O}_{2}$ is representative of the operating condition with high smoke emissions and $9 \% \mathrm{O}_{2}$ is for smokeless combustion in the general cases [16-19]. The ignition timing is defined by the crank angle with $5 \%$ of the accumulated apparent heat release. The premixing time is defined by the period from the end of fuel injection to the onset of the ignition, and it is given by subtracting the injection duration from the ignition delay. Therefore, the negative values of the premixing time represent the ignition during the fuel injection. It must be pointed out that a decrease in the intake oxygen concentration to $9 \%$ with EGR results in misfiring for the fuel of cetane number 34. The lower the cetane number is, the more the advanced fuel injection or decreased intake oxygen content causes the ignition delay or premixing time to increase. It is noteworthy that the premixing time is around zero with cetane number 94, indicating that ignition occurs around the end of fuel injection, regardless of the injection timing and intake oxygen concentration.

Figure 3 shows the effect of premixing time on the maximum rate of pressure rise $\left(d p / d \theta_{\max }\right)$ and the exhaust gas emissions measured for two intake oxygen concentrations, various cetane numbers, and injection timings. At all premixing times, the NOx emissions are suppressed to levels below 0.6 $\mathrm{g} /\left(\mathrm{kW}_{\mathrm{i}} \cdot \mathrm{h}\right)$ (gram per indicated work) with the $12 \%$ intake oxygen concentration, and these emissions are further reduced to below $0.1 \mathrm{~g} /\left(\mathrm{kW}_{\mathrm{i}} \cdot \mathrm{h}\right)(10 \mathrm{ppm})$ when decreasing the intake oxygen concentration to 9\%. With the premixing time longer than $4{ }^{\circ} \mathrm{CA}$, that is ignition occurred at times later than $4{ }^{\circ} \mathrm{CA}$ after the end of fuel injection, smokeless combustion is established regardless of the intake oxygen concentration, cetane number, and injection timing. When the premixing time is shorter than $4{ }^{\circ} \mathrm{CA}$, smoke 
emissions increase sharply with the premixing time decreasing in most cases, but there is case of smokeless combustion at this condition. For example, despite the low oxygen concentration at $9 \%$, the premixing time is around zero with cetane number 94 for all injection timings. There are significant amount of smoke emissions with the injection timings earlier than $-15{ }^{\circ} \mathrm{CA}$ ATDC because the advanced injection leads to too early combustion phasing and high combustion temperature, but smokeless combustion is established with the injections at -6 and $-10{ }^{\circ} \mathrm{CA}$ ATDC owing to the lowered combustion temperature. In this case of smokeless combustion with 9\% oxygen and insufficient mixing time, however, the UHC and CO emissions are significantly higher than when the premixing time is adequate. Advancing the fuel injection timing is effective to extend the premixing time and improve the fuel-air mixing, but with the high intake oxygen concentration and high cetane numbers, this strategy significantly increases the maximum rate of pressure rise and the engine noise. At $9 \%$ oxygen, the maximum rate of pressure rise can be suppressed to below $1.0 \mathrm{MPa} /{ }^{\circ} \mathrm{CA}$ for all premixing times. While the UHC and CO emissions show apparently higher concentrations with the $9 \%$ intake oxygen than with $12 \%$ oxygen, with the premixing time increasing, these emissions decrease at first, reach lowest values, and then increase again at 9\% oxygen. This suggests that while local insufficient mixing (too short premixing time) or overly-mixed fuel-air mixture (too long premixing time) could be the sources of the UHC and CO emissions, these emissions can be reduced with improved fuel-air mixing, and optimized two-stage injection could be effective to promote fuel-air mixing.

The effect of the two-stage injection on the UHC and CO emissions at the 9\% intake oxygen concentration is shown in Fig. 4. In the two-stage injection, 20\% of fuel was injected in the first injection that started at $-35{ }^{\circ} \mathrm{CA}$ ATDC and completed at $-29{ }^{\circ} \mathrm{CA}$ ATDC and the second injection timing $\left(\mathrm{t}_{2 \mathrm{ndsoI}}\right)$ was varied. Here note that the injection timing is based on the measured signal of needle valve lift, and the two-stage injection with the second injection started at $-29{ }^{\circ} \mathrm{CA}$ ATDC is different from the single injection started at $-35{ }^{\circ} \mathrm{CA}$ ATDC. For example, owing to the injector needle dynamics, the total injection duration of two-stage injection is $16{ }^{\circ} \mathrm{CA}$, which is apparently longer than $11^{\circ} \mathrm{CA}$ for the single injection. For comparison, the data with the single injection around TDC ignition under the same conditions as in Fig. 3 and the data with 12\% oxygen are also plotted in Fig. 4. The UHC and CO emissions 
are somewhat lower with the two-stage injection compared to those with the single injection with $9 \%$ oxygen, but the emissions are still at apparently higher levels than those with $12 \%$ oxygen. Note that the NOx emissions are below $0.1 \mathrm{~g} /\left(\mathrm{kW}_{\mathrm{i}^{\cdot}} \mathrm{h}\right)$ at $9 \%$ oxygen (Fig. 3), regardless of the various injection strategies.

Figure 5 shows the rate of heat release with the single injection starting at $-35{ }^{\circ} \mathrm{CA}$ ATDC and the two-stage injection under the same conditions as in Fig. 4. The two-stage injection with the second injection starting at $-29^{\circ} \mathrm{CA}$ ATDC exhibits a higher peak rate of heat release than the single injection, though the ignition timings are almost identical. Retardation of the second injection to $-24{ }^{\circ} \mathrm{CA}$ ATDC leads to an about 2 degree advance in the ignition timing. These results can be attributed to the increase in combustible mixture available with the two-stage injection. However, the two-stage injection with further retarded second injection results in ignition delays and slower rates of heat release, and with the second injection later than $-15{ }^{\circ} \mathrm{CA}$ ATDC, the combustion becomes unstable. This is in good agreement with the trends in the UHC and CO emissions shown in Fig. 4.

When holding the dwell between the two injections at $5{ }^{\circ} \mathrm{CA}$ and the first injection timing at $-35^{\circ} \mathrm{CA}$ ATDC, the effect of the size of the fuel fraction in the first injection on the UHC and CO emissions is shown in Fig. 6. Decreases in the fuel fraction in the first injection are advantageous to reductions in the UHC and CO emissions, but these emissions are still at fairly high levels. Here, either an increased dwell or a retarded first injection at 9\% oxygen will lead to ignition after TDC, which would significantly increase the UHC and CO emissions.

\subsection{Effect on the mixture formation processes of single injection with various injection timings}

Figure 7 shows the simulated fuel spray and mixture distributions at $6{ }^{\circ} \mathrm{CA}$ after the start of injection, and Figure 8 shows the simulated mixture distributions at TDC, for various fuel injection timings. The results here and in the following sections represent the cross-sections including the spray direction and the piston-bowl center. Note that Figs 8 (a) and (b) are based on the same set of data, but the scale of the color bar for the equivalence ratios ( $\phi$ ) is different to make it better possible to distinguish the fuel rich and lean areas in the mixture. As shown in Fig. 8 (a), with the injection timing at $10{ }^{\circ} \mathrm{CA}$ BTDC, 
the fuel injection is still in progress at TDC, and there are significant amounts of mixture with equivalence ratios above 2.0. With TDC ignition, these under-mixing over-rich mixtures would have difficulty in burning completely with low combustion temperatures in the low-oxygen environments, resulting in the increases in the UHC and CO emissions shown in Fig. 4. Advances in the injection timing, using low cetane number fuels, help to extend the ignition delay, reduce the over-rich mixture at TDC as shown in Fig. 8 (a), and this strategy results in a decrease in the UHC and CO emissions as shown in Fig. 4. However, too early injection, for example at $35^{\circ} \mathrm{CA}$ BTDC as shown in Fig. 7, results in spray impinging upon the lip of the piston cavity, and significant amounts of fuel-rich mixture would miss the piston bowl and enter the squish zone between the piston top and cylinder head at TDC as shown in Fig. 8 (a). These mixtures with equivalence ratios above 2.0 are very difficult to burn completely in low temperature and low oxygen environments. Particularly, in the case of TDC ignition, owing to the cooling effect of the gas expansion, these mixtures may be subject to temperatures even lower than the temperatures necessary for UHC conversion to $\mathrm{CO}$, resulting in the increases in UHC and the decreases in CO as shown in Fig. 4.

\subsection{Effect of two-stage injection with various dwells on mixture formation processes}

Figure 9 shows the mixture distribution after the start of the first injection in the two-stage injection, with $20 \%$ fuel injected in the first injection at $35{ }^{\circ} \mathrm{CA}$ BTDC and with $5{ }^{\circ} \mathrm{CA}$ dwell between the end of the first injection and start of the second injection. Here the injection timings are based the measured values of the needle lift in the experiments. Even when the fuel spray in the first injection is directed at the lip of the piston cavity, the injected quantity is very small, and the droplets will evaporate and lose momentum quickly. As a result, the mixture does not penetrate very far into the squish zone. The fuel spray in the second injection is almost completely caught in the piston cavity. As a result, there is little mixture with equivalence ratios above 2.0 in the squish zone. This relates well to the reductions in the UHC and CO emissions as shown in Fig. 4. As shown in Fig. 10, however, there are significant amounts of mixture with equivalence ratios below 0.5 , which could be one reason why the UHC and CO emissions are still at high levels, even with the two-stage injection. 
Figure 11 shows the mixture distribution at TDC for the two-stage injection with the second injection timing varied. Retarding the second injection can decrease the mixtures with equivalence ratios from 0.2 to 0.5 . However, mixture volumes with equivalence ratios below 0.2 increase, though these mixtures would account for only a small percentage in the total injected quantity. Further, when the second injection is retarded to later than $20^{\circ} \mathrm{CA} \mathrm{BTDC}$, mixtures with equivalence ratios above 2.0 significantly increase along the wall of the piston cavity. These mixtures would be very difficult to completely burn with the retarded combustion phasing as shown in Fig. 5. This could provide an explanation for the increases in the UHC and CO emissions with the retarded second injection as shown in Fig. 4.

\section{CONCLUSIONS}

The effects of two-stage injection on the UHC and CO emissions with smokeless low temperature diesel combustion at ultra-high EGR were investigated with engine experiments, and the mixture formation processes were studied with CFD simulations to explain the effects of the two-stage injection. With optimized dwell and injection ratio, the two-stage injection can reduce the UHC and CO emissions, but these emissions are still at fairly high levels in the ultra-high EGR smokeless LTC regime. The reductions in the UHC and CO emissions with the two-stage injection can be attributed mainly to the fact that the fuel-rich mixtures in the squish zone are circumvented and the improved fuel-air mixing leads to faster rates of heat release. However, the over-lean mixtures at the center of the combustion chamber are little reduced with the two-stage injection, and they would be a significant source of the UHC and CO emissions, in addition to the generally known sources of UHC and CO emissions. These results suggest that improvements in fuel-air mixing at relatively high intake oxygen concentrations ( $12 \%$ in this study) are necessary to simultaneously reduce the soot and NOx emissions while keeping the UHC and CO emissions at low levels.

\section{REFERENCES}

1 Dec, J.E. A conceptual model of DI diesel combustion based on laser-sheet imaging. SAE paper 970873, 1997. 
2 Emissions regulations may be found at: http://www.dieselnet.com/standards/.

3 Dec, J.E. Advanced compression-ignition engines - understanding the in-cylinder processes. Proc. Combst. Inst., 2009, 32, 2727-2742.

4 Yao M., Zheng Z., and Liu H. Progress and recent trends in homogeneous charge compression ignition (HCCI) engines. Prog. Energ. Combst. Sci., 2009, 35, 398-437.

5 Takeda, Y., and Keiichi, N. Emission characteristics of premixed lean diesel combustion with extremely early staged fuel injection. SAE paper 961163, 1996.

6 Akagawa, H., Miyamoto, T., Harada, A., Sasaki, S., Shimazaki, N., and Hashizumi, T. Approaches to solve problems of the premixed lean diesel combustion. SAE paper 1999-01-0183, 1999.

7 Hasegawa, R., and Yanagihara, H. HCCI combustion in DI diesel engine. SAE paper 2003-01-0745, 2003.

8 Kimura, S., Aoki, O., Ogawa, H., Muranaka, S., and Enomoto, Y. New combustion concept for ultra-clean and high-efficiency small DI diesel engines. SAE Paper 1999-01-3681, 1999.

9 Akihama, K., Takatori, Y., Inagaki, K., Sasaki, S., and Dean, A.M. Mechanism of the smokeless rich diesel combustion by reducing temperature. SAE paper 2001-01-0655, 2001.

10 Shimazaki, N., Tsurushima, T., and Nishimura, T. Dual-mode combustion concept with premixed diesel combustion by direct injection near top dead center. SAE paper 2003-01-0742, 2003.

11 Pickett, L. M. Non-sooting, low flame temperature mixing-controlled DI diesel combustion. SAE paper 2004-01-1339, 2004.

12 Neely, G. D., Sasaki, S., Huang, Y., Leet, J. A., and Stewart, D. W. New diesel emission control strategy to meet US Tier 2 emissions regulations. SAE paper 2005-01-1091, 2005.

13 Alriksson, M., Rente, T., and Denbratt, I. Low soot, low NOx in a heavy duty diesel engine using high levels of EGR. SAE paper 2005-01-3836, 2005.

14 Kook, S., Bae, C., Miles, P., Chio, D., and Picket, L. M. The influence of charge dilution and injection timing on low-temperature diesel combustion and emissions. SAE paper 2005-01-3837, 2005. 
15 Noehre, C., Anderson, M., Johansson, B., and Hultqvist, A. Characterization of partially premixed combustion. SAE paper 2006-01-3412, 2006.

16 Ogawa, H., Li, T., and Miyamoto, N. Characteristics of low temperature and low oxygen diesel combustion with ultra-high exhaust gas recirculation. Int. J. Engine Res., 2007, 8(4), 365-378.

17 Li, T., Suzuki, M., and Ogawa, H. Effects of ethyl tert-butyl ether addition to diesel fuel on characteristics of combustion and exhaust emissions of diesel engines. Fuel, 2009, 88: 2017-2024.

18 Li, T., Suzuki, M., Shudo, T., and Ogawa, H. Effect of cetane number on mixture formation and combustion characteristics of ultra-high EGR low temperature diesel combustion. Review of Automotive Engineering (JSAE Review), 2008, 39 (3), 157-162.

19 Li, T., Suzuki, M., and Ogawa, H. Characteristics of smokeless low temperature diesel combustion in various fuel-air mixing and expansion of operating load range. SAE Paper 2009-01-1449, 2009.

20 Greeves, G., Khan, T. M., Wang, T., and Fenne, T. Origins of hydrocarbon emissions from Diesel engines. SAE paper 770259, 1977.

21 Heywood, J. B. Internal combustion engines fundamentals, McGram-Hill, Inc., 1988, p.625.

22 Musculus, M., Lachaux, T., Pickett, L., and Idicheria, C. End-of-injection over-mixing and unburned hydrocarbon emissions in low-temperature-combustion diesel engines. SAE paper 2007-01-0907, 2007.

23 Kim, D., Ekoto, I., Colban, W., and Miles, P. In-cylinder CO and UHC imaging in a light-duty diesel engine during PPCI low-temperature combustion. SAE paper 2008-01-1602, 2008.

24 Ekoto, I., Colban, W., Miles, P., Park, S., Foster, D., and Reitz, R. D. Sources of UHC emissions from a light-duty diesel engine operating in a partially premixed combustion regime. SAE paper 2009-01-1446, 2009.

25 Opat, R., Ra, Y., Gonzalez, D., Krieger, R., Reitz, R., Foster, D., Durrett, R., and Sievert, R. Investigation of mixing and temperature effects on $\mathrm{HC} / \mathrm{CO}$ emissions for highly dilute low temperature combustion in a light duty diesel engine. SAE Paper 2007-01-0193, 2007. 
26 Tow, T., Pierpont, A., and Reitz, R.D. Reducing particulate and NOx by using multiple injections and EGR in a heavy duty DI diesel engine. SAE Paper 940897, 1994.

27 Montgomery, D.T., and Reitz, R.D. Six-mode cycle evaluation of the effect of EGR and multiple injections on particulate and NOx emissions from a DI diesel engine. SAE Paper 960316, 1996.

28 Han, Z., Uludogan, A., Hampson, G.J., and Reitz, R.D. Mechanism of soot and NOx emission reduction using multiple-injection in a diesel engine. SAE Paper 960633, 1996.

29 Zhang, Y., Itoh,T.,and Nishida, K. Characterization of mixture formation in split-Injection diesel sprays via laser absorption-scattering (LAS) technique. SAE Paper 2001-01-3498, 2001.

30 Horibe, N., Harada, S., Ishiyama, T., and Shioji, M. Improvement of low-temperature combustion by two-stage injection. Proc. COMODIA, 2008, 7, 159-166.

31 Koci, P., Ra, Y., Andrie, M., Krieger, R., Foster, D., Siewert, R.M., and Durrett R. Multiple event fuel injection investigations in a highly-dilute diesel low temperature combustion regime. SAE paper 2009-01-0925, 2009.

32 Heywood J.B. Internal Combustion Engine Fundamentals. McGraw-Hill, Inc., 1988, p.510.

33 Liu, A. B., Mather, D., and Reitz, R. D. Modeling the effects of drop drag and breakup on fuel sprays. SAE paper 930072, 1993.

34 Naber, J. D., and Reitz, R. D. Modeling engine spray/wall impingement. SAE paper 880107, 1988.

\section{APPENDIX}

\section{Notation}

$\phi \quad$ : equivalence ratio

$T \quad$ : temperature

$d p / d \theta_{\max }:$ maximum rate of pressure rise

$t_{\text {SOI }} \quad$ : injection timing

$\mathrm{t}_{2 n d s o I} \quad$ injection timing of second injection in two-stage injection 
$\theta_{\text {pre }} \quad$ : premixing time
Subscript
in : intake
$\max \quad$ : maximum
pre : premixing
SOI : start of injection

Acronyms

ATDC : after top dead center

BTDC : before top dead center

CFD : computational fluid dynamics

$\mathrm{CN}$ : cetane number

D : dimensional

DI : direct injection

EGR : exhaust gas recirculation

IMEP : indicated mean effective pressure

IP : iso-paraffins

NOx : oxides of nitrogen

NP : n-paraffins

$\mathrm{O}_{\text {2in }} \quad$ : intake oxygen concentration

RF : reference fuel

ROHR : rate of heat release

TDC : top dead center

UHC : unburned hydrocarbons

CO : carbon monoxide

${ }^{\circ} \mathrm{CA} \quad$ : crank angle degree 
List of captions for the tables

Table 1 Engine specifications

Table 2 Test conditions

Table 3 Properties of test fuels

Table 4 Sub-models and initial conditions 
Table 1 Engine specifications

\begin{tabular}{ll}
\hline Cylinder number & 1 \\
Bore $\times$ Stroke & $\varnothing 110 \times 106 \mathrm{~mm}$ \\
Displacement & $1007 \mathrm{~cm}^{3}$ \\
Piston cavity shape & Toroidal \\
Rated power & $11.8 \mathrm{~kW} @ 2200 \mathrm{rpm}$ \\
Compression ratio & 16.0 \\
Swirl ratio & 2.2 \\
Intake system & Naturally aspirated \\
Valve number & 2 \\
Fuel injection system & Common rail system \\
Nozzle hole & $\varnothing 0.20 \times 4-150^{\circ}$ \\
\hline
\end{tabular}

Table 2 Test conditions

\begin{tabular}{ll}
\hline Engine speed & $1320 \mathrm{rpm}$ \\
Coolant temperature & $80^{\circ} \mathrm{C}$ \\
Injection pressure & $120 \mathrm{MPa}$ \\
Injection quantity & $32 \mathrm{~mm}^{3} /$ stroke \\
Injection timing & Dynamically controlled \\
Intake temperature & $30 \pm 3^{\circ} \mathrm{C}$ \\
\hline
\end{tabular}

Table 3 Properties of test fuels

\begin{tabular}{llllllll}
\hline Fuel property & Unit & NP & IP & RF6-4 & RF5-5 & RF3-7 & RF2-8 \\
\hline Density @15 ${ }^{\circ} \mathrm{C}$ & $\mathrm{kg} / \mathrm{m}^{3}$ & 760 & 789 & 772 & 775 & 781 & 784 \\
Kinematic viscosity @30 ${ }^{\circ} \mathrm{C}$ & $\mathrm{mm}^{2} / \mathrm{s}$ & 2.05 & 3.20 & 2.51 & 2.62 & 2.85 & 2.97 \\
Cetane number & - & 94 & 19 & 64 & 57 & 42 & 34 \\
50\% distillation temp. & ${ }^{\circ} \mathrm{C}$ & 231 & 236 & 233 & 233 & 234 & 235 \\
Lower heating value & $\mathrm{MJ} / \mathrm{kg}$ & 43.9 & 43.8 & 43.9 & 43.9 & 43.8 & 43.8 \\
\hline
\end{tabular}

Table 4 Sub-models and initial conditions

\begin{tabular}{ll}
\hline Spray & Discrete Droplet Method \\
Breakup & WAVE [33] \\
Wall interaction & Wall jet [34] \\
Turbulence & $\kappa-\varepsilon$ model \\
EGR rate (cylinder $\left.\mathrm{O}_{2}\right)$ & $60 \%(9 \%)$ \\
Initial pressure & $0.12 \mathrm{MPa}$ \\
Initial temperature & $353 \mathrm{~K}$ \\
\hline
\end{tabular}




\section{List of captions for the illustrations}

Fig. 1 Mesh arrangement used in the CFD simulations

Fig. 2 Effects of fuel cetane number and injection timing on the premixing time and ignition delay for $12 \%$ and $9 \%$ intake oxygen concentrations (50\% and 60\% EGR). The injection duration for all fuels is $11^{\circ} \mathrm{CA}$.

Fig. 3 Premixing time vs. the maximum rate of pressure rise and exhaust gas emissions for two intake oxygen concentrations, various cetane numbers, and injection timings.

Fig. 4 Effect of two-stage injection on UHC and CO emissions at 9\% intake oxygen concentration with RF3-7. Filled stars: two-stage injection with $20 \%$ fuel injected in the first injection started at $-35{ }^{\circ} \mathrm{CA}$ ATDC and completed at $-29{ }^{\circ} \mathrm{CA}$ ATDC and the second injection time sweeping, and the duration of second injection is $10{ }^{\circ} \mathrm{CA}$. Other filled symbols: single injection around TDC ignition at 9\% intake oxygen concentration under the same conditions as in Fig.2. The open symbols: emissions at $12 \%$ intake oxygen concentration under the same conditions as in Fig.2.

Fig. 5 The rate of heat release for the single injection started at $-35{ }^{\circ} \mathrm{CA}$ ATDC and the two-stage injection with the first injection started at $-35{ }^{\circ} \mathrm{CA}$ ATDC and the second injection sweeping. Fuel: RF3-7. Intake oxygen concentration: 9\%.

Fig. 6 UHC and $\mathrm{CO}$ emissions vs. fuel injection fraction in the first injection at $-35{ }^{\circ} \mathrm{CA}$ ATDC with a fixed dwell of $5{ }^{\circ} \mathrm{CA}$. Intake oxygen concentration: $9 \%$.

Fig. 7 Simulated fuel spray and mixture distributions at $6{ }^{\circ} \mathrm{CA}$ after start of injection for various injection timings of single injection.

Fig. 8 Mixture distribution at top dead center for various fuel injection timings of single injection. (a) For the fuel rich areas (b) For the lean areas

Fig. 9 Mixture distribution after start of the first injection of the two-stage injections. The $20 \%$ fuel injected in the first injection starting at $35^{\circ}$ and finishing at $29^{\circ} \mathrm{CA}$ BTDC; the second injection starting at $24^{\circ}$ and finishing at $14^{\circ} \mathrm{CA}$ BTDC.

Fig. 10 Mixture distribution at top dead center for the two-stage injection under the conditions in Fig.8.

Fig. 11 Mixture distribution at top dead center for the two-stage injection with the second injection sweeping. The 20\% fuel injected in the first injection started at $35^{\circ}$ and finished at $29^{\circ} \mathrm{CA}$ BTDC. (a) For the fuel rich areas (b) For the lean areas 


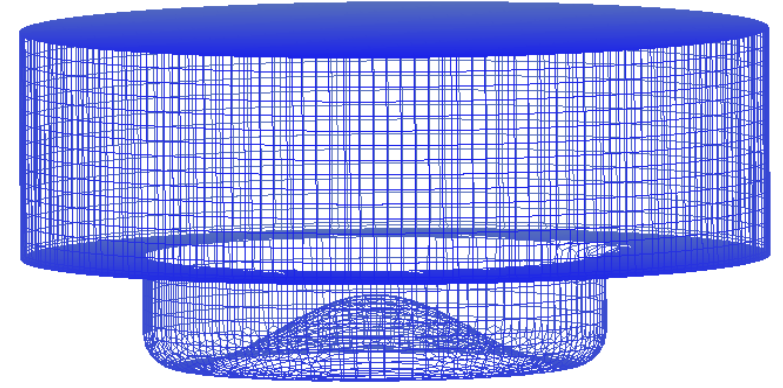

Fig. 1 Mesh arrangement used in the CFD simulations 


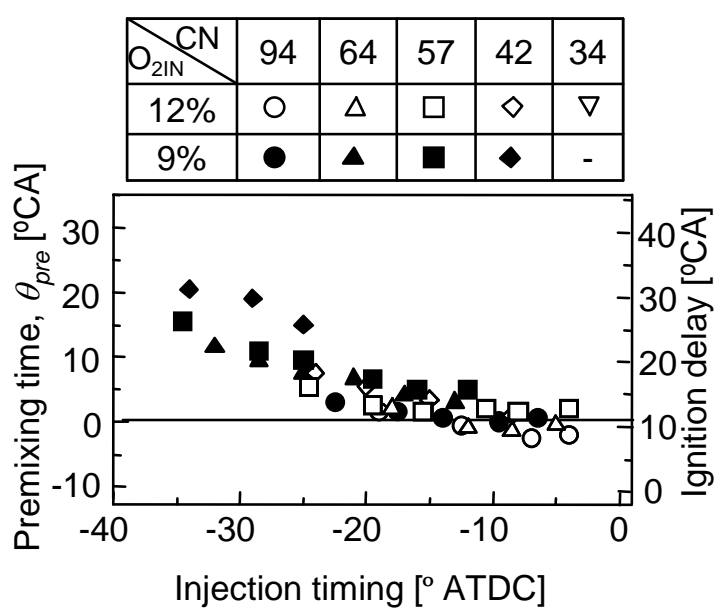

Fig. 2 Effects of fuel cetane number and injection timing on the premixing time and ignition delay for $12 \%$ and $9 \%$ intake oxygen concentrations (50\% and 60\% EGR). The injection duration for all fuels is $11^{\circ} \mathrm{CA}$. 


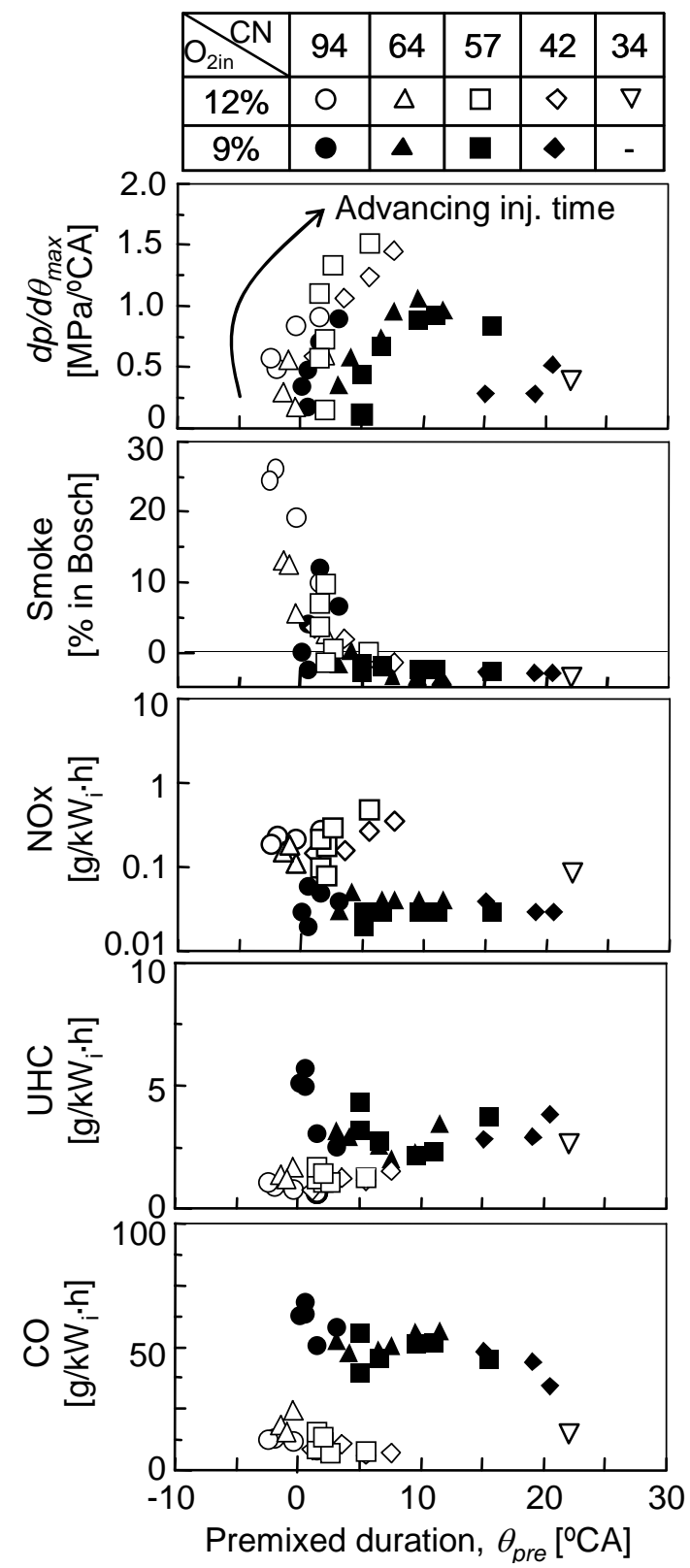

Fig. 3 Premixing time vs. the maximum rate of pressure rise and exhaust gas emissions for two intake oxygen concentrations, various cetane numbers, and injection timings. 


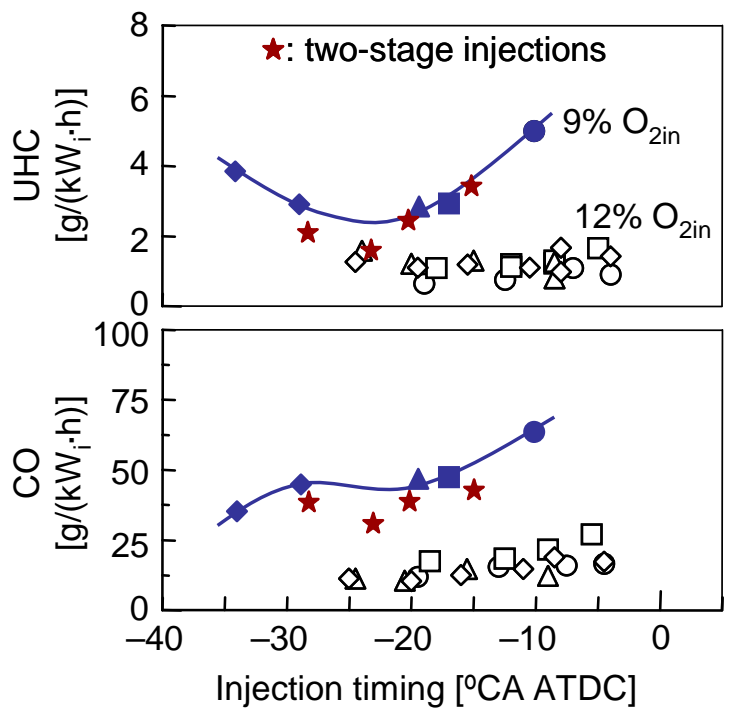

Fig. 4 Effect of two-stage injection on UHC and CO emissions at 9\% intake oxygen concentration with RF3-7. Filled stars: two-stage injection with 20\% fuel injected in the first injection started at $-35{ }^{\circ} \mathrm{CA}$ ATDC and completed at $-29{ }^{\circ} \mathrm{CA}$ ATDC and the second injection time sweeping, and the duration of second injection is $10{ }^{\circ} \mathrm{CA}$. Other filled symbols: single injection around TDC ignition at 9\% intake oxygen concentration under the same conditions as in Fig.2. The open symbols: emissions at $12 \%$ intake oxygen concentration under the same conditions as in Fig.2. 


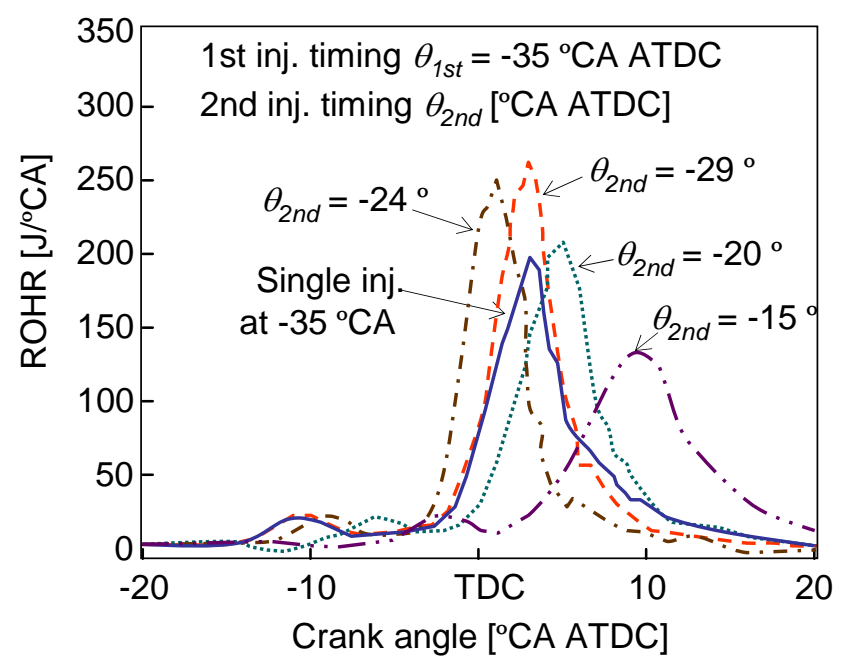

Fig. 5 The rate of heat release for the single injection started at $-35{ }^{\circ} \mathrm{CA}$ ATDC and the two-stage injection with the first injection started at $-35{ }^{\circ} \mathrm{CA}$ ATDC and the second injection sweeping. Fuel: RF3-7. Intake oxygen concentration: 9\%. 

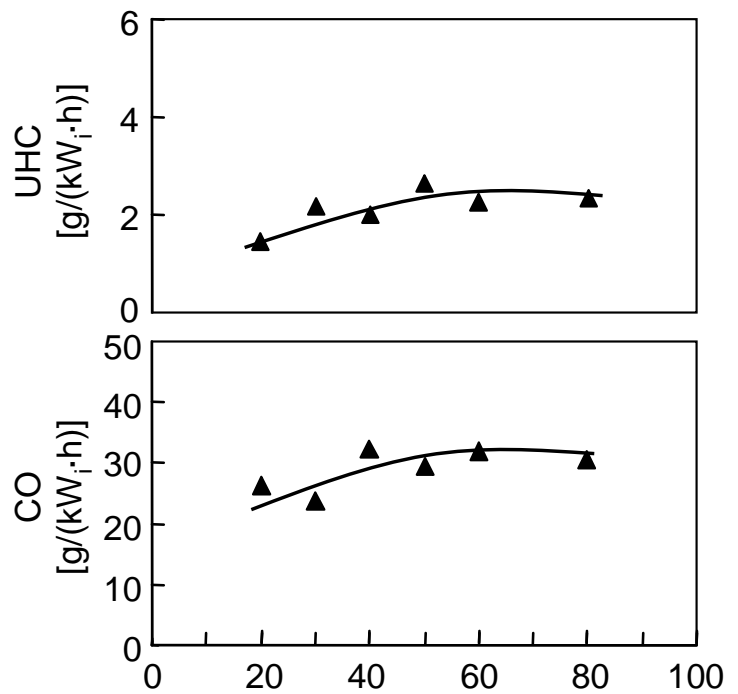

Fuel fraction in the first injection [\%]

Fig. 6 UHC and CO emissions vs. fuel injection fraction in the first injection at $-35^{\circ} \mathrm{CA}$ ATDC with a fixed dwell of $5{ }^{\circ} \mathrm{CA}$. Intake oxygen concentration: $9 \%$. 


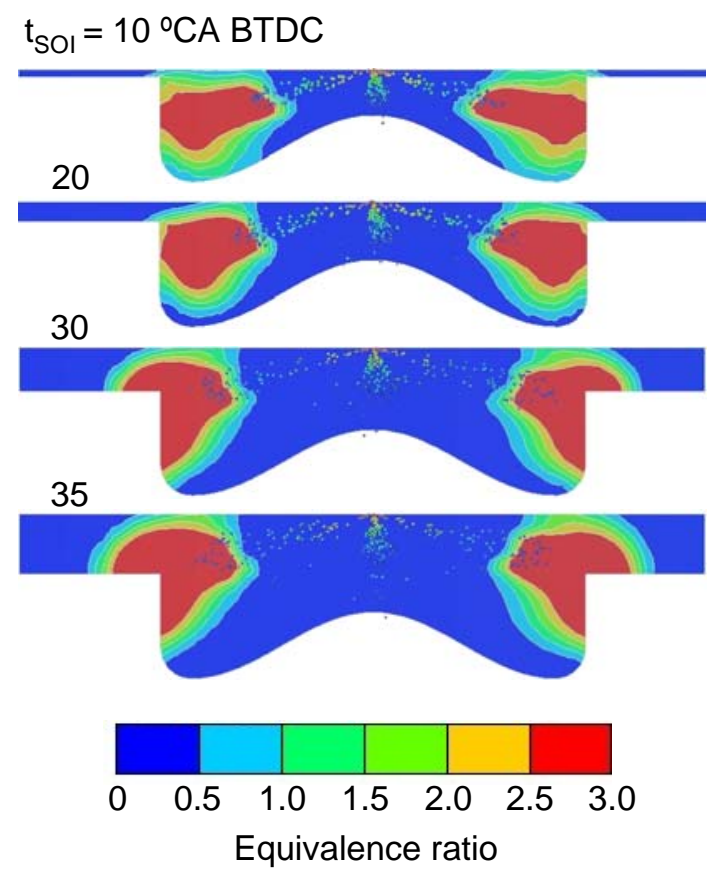

Fig. 7 Simulated fuel spray and mixture distributions at $6{ }^{\circ} \mathrm{CA}$ after start of injection for various injection timings of single injection. 


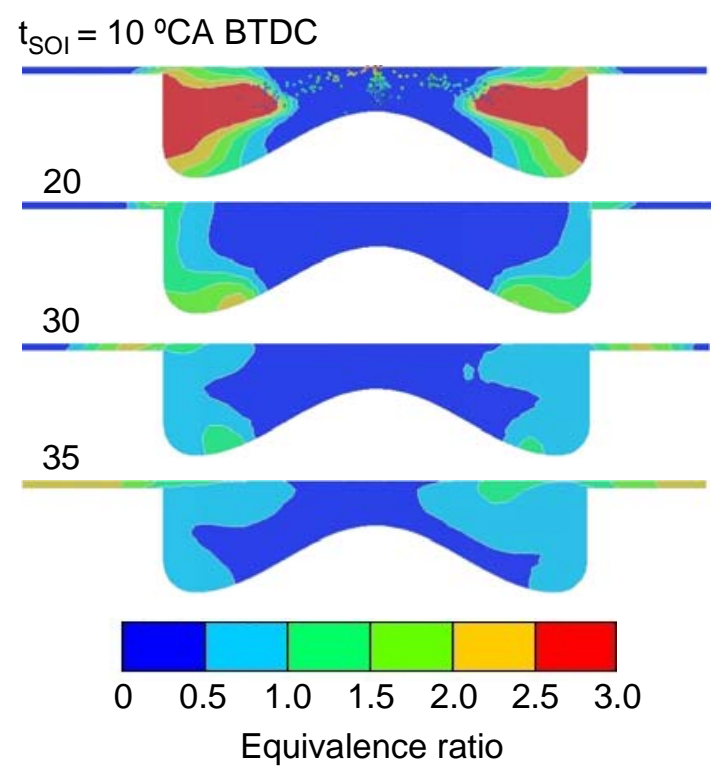

(a) For the fuel rich areas

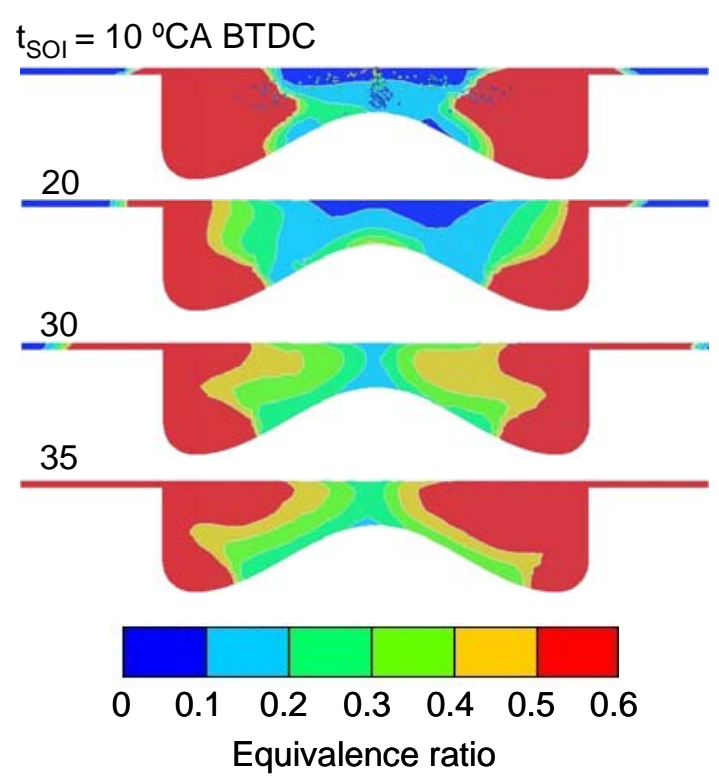

(b) For the lean areas

Fig. 8 Mixture distribution at top dead center for various fuel injection timings of single injection. 
$30^{\circ} \mathrm{CA}$ BTDC after start of first injection

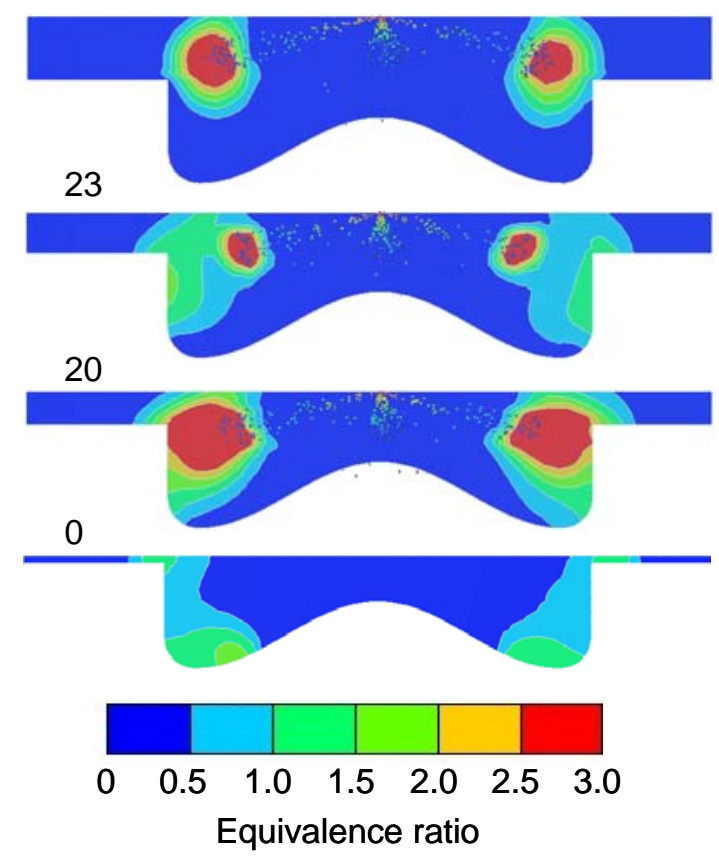

Fig. 9 Mixture distribution after start of the first injection of the two-stage injections. The $20 \%$ fuel injected in the first injection starting at $35^{\circ}$ and finishing at $29^{\circ} \mathrm{CA} B \mathrm{BTC}$; the second injection starting at $24^{\circ}$ and finishing at $14^{\circ} \mathrm{CA}$ BTDC. 


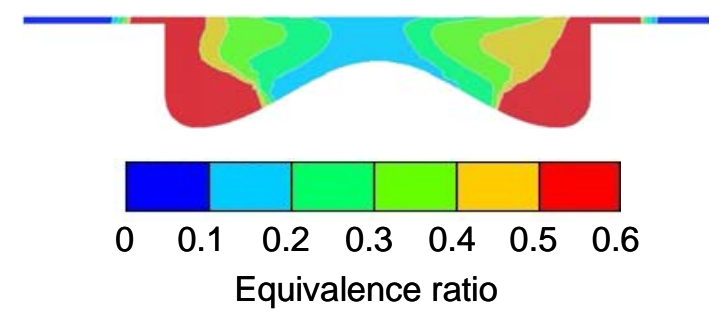

Fig. 10 Mixture distribution at top dead center for the two-stage injection under the conditions in Fig.8. 


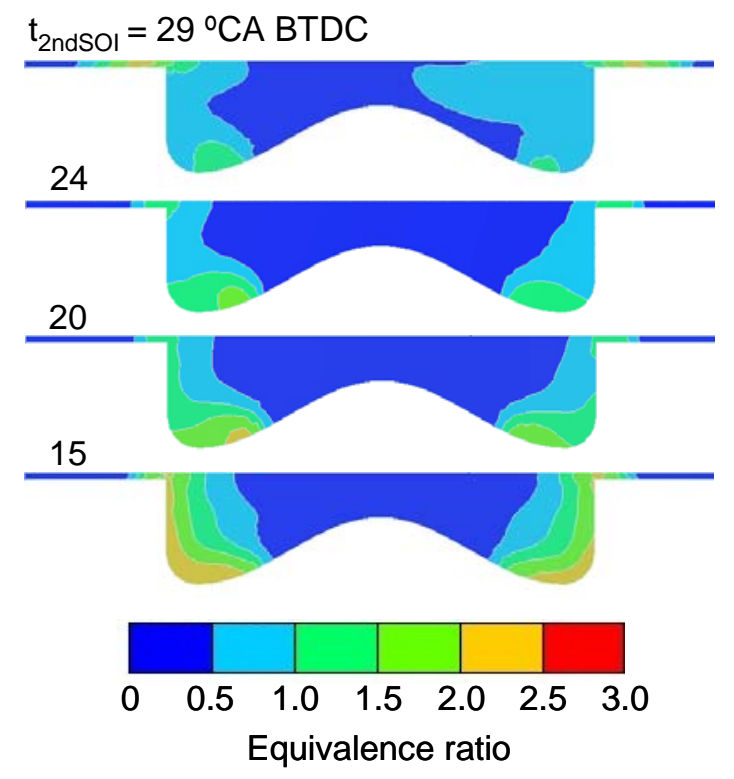

(a) For the fuel rich areas

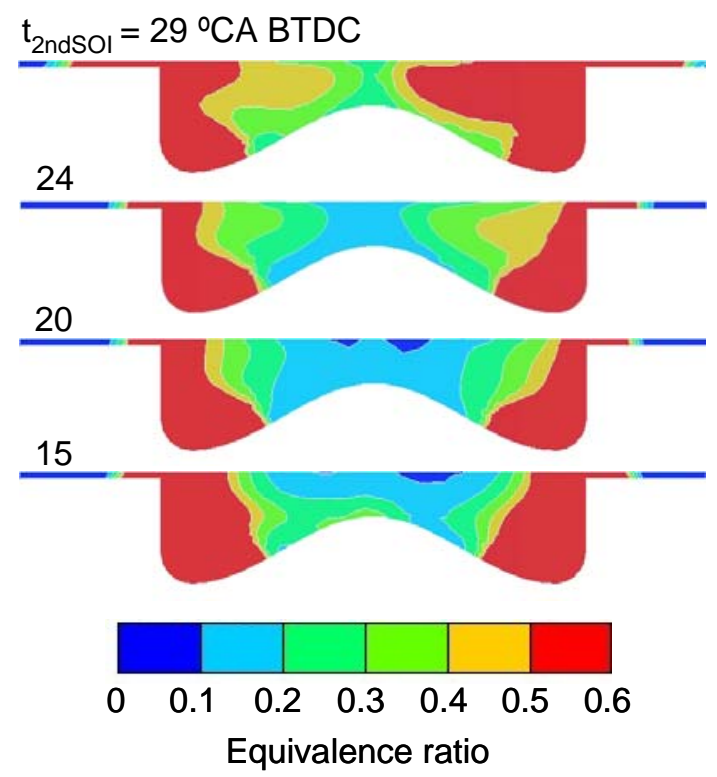

(b) For the lean areas

Fig. 11 Mixture distribution at top dead center for the two-stage injection with the second injection sweeping. The $20 \%$ fuel injected in the first injection started at $35^{\circ}$ and finished at 29 ${ }^{\circ}$ CA BTDC. 